\title{
Factors associated with delayed initiation of breastfeeding in health facilities: secondary analysis of Bangladesh demographic and health survey 2014
}

\author{
Shahreen Raihana ${ }^{1,2^{*}}$ D, Ashraful Alam ${ }^{1}$, Tanvir M. Huda ${ }^{1,2}$ and Michael J. Dibley ${ }^{1}$
}

\begin{abstract}
Background: Irrespective of the place and mode of delivery, 'delayed' initiation of breastfeeding beyond the first hour of birth can negatively influence maternal and newborn health outcomes. In Bangladesh, 49\% of newborns initiate breastfeeding after the first hour. The rate is higher among deliveries at a health facility (62\%). This study investigates the maternal, health service, infant, and household characteristics associated with delayed initiation of breastfeeding among health facility deliveries in Bangladesh.

Methods: We used data from the 2014 Bangladesh Demographic and Health Survey. We included 1277 last-born children born at a health facility in the 2 years preceding the survey. 'Delayed' breastfeeding was defined using WHO recommendations as initiating after $1 \mathrm{~h}$ of birth. We performed univariate and multivariable logistic regression to determine factors associated with delayed initiation.

Results: About three-fifth $(n=785,62 \%)$ of the children born at a health facility delayed initiation of breastfeeding beyond $1 \mathrm{~h}$. After adjusting for potential confounders, we found delayed initiation to be common among women, who delivered by caesarean section (adjusted Odds Ratio (aOR): 2.93; $95 \% \mathrm{Cl} 2.17,3.98$ ), and who were exposed to media less than once a week (aOR: 1.53; 95\% Cl 1.07, 2.19). Women with a higher body mass index had an increased likelihood of delaying initiation (aOR: 1.05; $95 \% \mathrm{Cl} 1.01,1.11$ ). Multiparous women were less likely to delay (aOR: 0.71; 95\% Cl 0.53, 0.96).

Conclusions: Delayed initiation of breastfeeding following caesarean deliveries continues to be a challenge, but several other health facility and maternal factors also contributed to delayed initiation. Interventions to promote early breastfeeding should include strengthening the capacity of healthcare providers to encourage early initiation, especially for caesarean deliveries.
\end{abstract}

Keywords: Breastfeeding, Initiation, Bangladesh demographic and health survey 2014, Caesarean, Health facilities

\footnotetext{
*Correspondence: srai7309@uni.sydney.edu.au; shahreenraihana@gmail.com

${ }^{1}$ Sydney School of Public Health, Faculty of Medicine and Health, The

University of Sydney, Sydney, New South Wales, Australia

${ }^{2}$ Maternal and Child Health Division, International Centre for Diarrhoeal

Disease Research, Bangladesh (icddr,b), Dhaka, Bangladesh
}

(c) The Author(s). 2021 Open Access This article is licensed under a Creative Commons Attribution 4.0 International License, which permits use, sharing, adaptation, distribution and reproduction in any medium or format, as long as you give appropriate credit to the original author(s) and the source, provide a link to the Creative Commons licence, and indicate if changes were made. The images or other third party material in this article are included in the article's Creative Commons licence, unless indicated otherwise in a credit line to the material. If material is not included in the article's Creative Commons licence and your intended use is not permitted by statutory regulation or exceeds the permitted use, you will need to obtain permission directly from the copyright holder. To view a copy of this licence, visit http://creativecommons.org/licenses/by/4.0/. The Creative Commons Public Domain Dedication waiver (http://creativecommons.org/publicdomain/zero/1.0/) applies to the data made available in this article, unless otherwise stated in a credit line to the data. 


\section{Background}

Global recommendations from WHO and UNICEF clearly state that all newborns are to be placed in 'skinto-skin contact' with their mother immediately after birth to 'support the initiation of breastfeeding within the first hour of birth [1,2]. Early initiation of breastfeeding within the first hour of birth is a crucial step towards ensuring optimal breastfeeding practices sustained throughout infancy. It supports the bond between mother and child [3], increases chances of breastfeeding success, and lengthens the duration of breastfeeding [4]. Mothers who delay the initiation of breastfeeding beyond the first hour would often also tend to terminate breastfeeding sooner than recommended.

Recent systematic reviews $[5,6]$ and a global report by WHO and UNICEF $[1,7]$ suggest that delaying initiation of breastfeeding beyond the first hour of birth increases the risk of neonatal death by $33 \%$. Studies in several low- and middle-income countries also report a $42-44 \%$ reduction in risk of death among newborns who initiated breastfeeding within the first hour of birth. Studies also suggest that timely initiation of breastfeeding enhances newborns immune system [8]. It is associated with reduced likelihood of mortality by protecting against infection [5, 9], sepsis and severe illnesses during early newborn [10], neonatal and infancy period.

The Baby Friendly Hospital Initiative and WHO [11] further emphasize that women would require assistance with positioning and attachment of the newborn to her breast. In circumstances when the mother has undergone a caesarean section, it is important to initiate breastfeeding as soon as the mother can respond [11, 12]. Mothers in the post-operative stage following a caesarean section at a health facility often require extra help [12] to position the newborn for its first suckle. Irrespective of the place of childbirth and mode of delivery, it is recommended to initiate breastfeeding before [1] the child has any routine procedures such as weighing, cord-cutting, bathing and wrapping.

Despite this evidence and guidelines emphasizing the importance of initiating breastfeeding early, the rate of early initiation of breastfeeding is still low in many developing countries. In Bangladesh, mothers exclusively breastfeed $55 \%$ of their infants under 6 months of age, a 13 percentage point increase over the past decade; and continue breastfeeding $87 \%$ of their infants until 2 years, a ten percentage point increase over the past decade. Only $51 \%$ of the newborns initiate breastfeeding within the first hour of birth $[13,14]$, which is a 27 percentage point increase from 2004 [15]. At the same time, institutional deliveries increased from $9 \%$ in 2004 to $39 \%$ in 2014. Yet, this increase has only translated into a modest decrease in the rate of delayed initiation of breastfeeding in Bangladesh $[14,15]$. According to the WHO tool for assessing infant and young child feeding practices [11], the current prevalence of early initiation of breastfeeding in Bangladesh is far below 90\%, the lower limit for "very good". Nationally representative data of Bangladesh [14] also suggests that the rate of delayed initiation is higher among deliveries that take place at health facilities. In $2014,62 \%$ of facility deliveries, and $41 \%$ of home deliveries, initiated breastfeeding after the first hour of birth [14], which appears contradictory to improved practices expected at health facilities.

Early initiation of breastfeeding, irrespective of the place and mode of delivery, is crucial in improving maternal and newborn health outcomes. However, there appears a gap in the practice to initiate breastfeeding within the first hour of birth, particularly among institutional deliveries in Bangladesh. This gap is an important area for research because we expect fewer women in these settings to experience delays as trained birth attendants should support them to initiate breastfeeding immediately after delivery. It is not clear which health service factors and maternal characteristics contribute to this consistent delay in breastfeeding initiation following delivery at a health facility. Such information can guide interventions to improve the maternal and newborn outcomes among institutional deliveries. The interventions required for home deliveries are likely to be very different for those occurring in facility deliveries. In this study, we investigate the factors associated with delayed initiation of breastfeeding among health facility deliveries in Bangladesh using data from the Demographic and Health Survey of Bangladesh, 2014.

\section{Methods}

\section{Study settings}

This study is a secondary analysis of data from the Bangladesh Demographic and Health Survey (DHS) 2014. This survey was conducted in 2013 and is a nationally representative survey that collected demographic and health-related data from 17,863 ever-married women aged 15-49 years from 17,300 households across Bangladesh. The DHS used a two-stage stratified sample of households from 600 enumeration areas (EA) (207 urban EA and 393 rural EA). The primary analysis performed using the DHS tools is reported in the Final Report of Bangladesh Demographic and Health Survey 2014 [14]. The DHS statistics manual [16] provides specific details of the sample design and data collection procedures. Data collection included administration of the Household and Woman's Questionnaire to collect information on the respondent's sociodemographic characteristics, birth history, and pregnancy and postnatal care. For this study, we restricted our sample size to women who delivered their last-born child born in the 2 years preceding the survey at a health facility. 


\section{Definition of variables \\ Outcome variable}

The outcome variable for this study is 'delayed initiation of breastfeeding' referring to any child for whom the mother, initiated breastfeeding after the first hour of birth. For this analysis, we coded delayed initiation of breastfeeding as a dichotomous variable of "within 1 hour" and "after 1 hour" for use in logistic regression models. We asked women who had a child born in the 2 years preceding the survey "How long after birth did you first put (child's name) to the breast?" Women who responded 'immediately' or 'within 0 or $1 \mathrm{~h}$ ' were coded as early initiators while all the rest we coded as delayed initiators. For this analysis to explore the determinants of delayed initiation, we have considered 'delayed initiation' as the outcome of interest. To examine the distribution of the outcome variable, we expanded the time to initiation of breastfeeding into four categories of 'within 1 h', '1-24 hours', '24-48 hours', and ' $\geq 48$ hours'.

\section{Exploratory variables}

We selected the variables from potential confounders of early initiation of breastfeeding identified in prior studies from other countries. Also, variable selection depended on the availability of the relevant data in the Bangladesh DHS 2014 [14].

The conceptual framework [17-19] (Fig. 1) summarises the selected potential individual and group level factors associated with the time of initiation of breastfeeding. We grouped these factors as i) maternal, ii) infant, iii) household, and iv) health service characteristics. We created categorical dummy variables by grouping continuous variables, using clinical and epidemiologic cut-offs. We treated the lowest group in each of the categories as the reference group to check the validity of the linear assumption. Group i) Maternal characteristics included mother's age, religion, mother's education, mother's involvement in income generation activities, parity, body mass index, exposure to mass media, use of a mobile phone to access health services and responsible for healthcare decisions. Mother's age was calculated by subtracting the child's age from the mother's age (self-reported) and recoded as < 20, 20-34 and 35-49 years. Islam is the most common religion in Bangladesh, and we recoded religion as 'Islam' and others. Mother's education was categorized as higher, secondary, primary and no education with the higher education as the reference group. Involvement in income generation activities coded into a dichotomous variable as employed and not employed (self-reported). We coded parity as primiparous (first birth) and multiparous (more than one birth). We recoded the person responsible for making healthcare decisions for the mother as 'woman herself', 'joint decision (including the woman)', and 'someone else (husband/family)'. We coded the extent of mother's exposure to mass media as 'at least once a week' versus 'less than once a week or not at all'. We used a dichotomous variable to record the mother's use

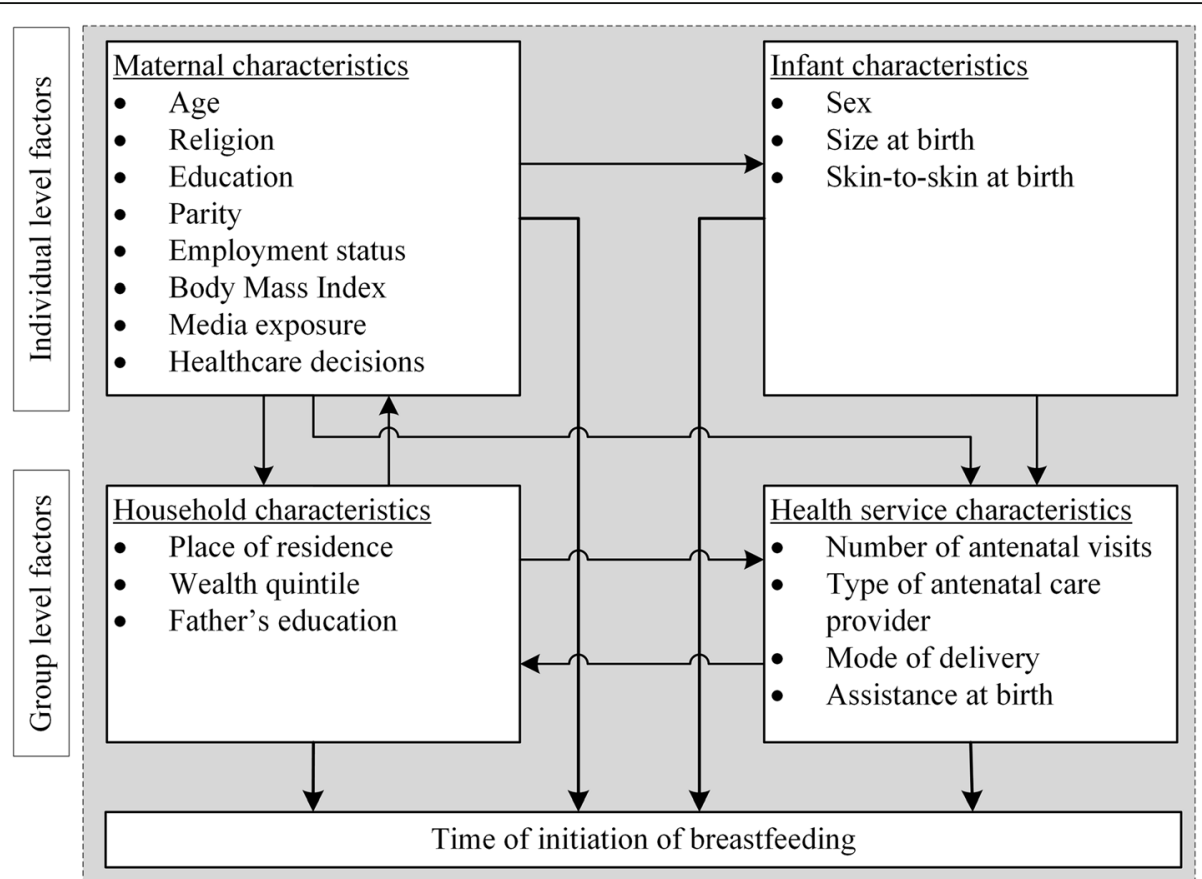

Fig. 1 Conceptual framework of individual and group level factors associated with the time of initiation of breastfeeding among deliveries in a health facility. Adapted from frameworks presented in earlier studies [17-19] with some modification 
of the mobile phone to get health services or advice. We treated body mass index (BMI) of the women as a continuous variable to assist interpretation. Group ii) We included the following infant characteristics in the analysis: sex of the child, size of child at birth, skin-to-skin contact after birth. Data on the birthweight of the child is not available in Bangladesh DHSs. The alternative information collected in the survey is the mother's perception of the size of the infant at birth which is a proxy for the objective measure of birth weight and often used in limited-resource settings [20]. For ease of interpretation, size of child at birth was coded as 'average or larger', 'smaller than average' and 'very small'. Skin-to-skin contact is the act of putting a naked child on to the mother's bare skin soon after birth. We created a dichotomous variable for whether the child had skin to skin contact immediately after birth. Group iii) Household characteristics included the father's education, place of residence, and wealth index. We coded the father's education, the same as the mother's education. Place of residence indicated whether the mother lived in urban or rural parts of the survey area. Since the DHS does not collect information on household income and expenditure, household' wealth index' was used as a proxy indicator for socio-economic status. We calculated the wealth index score using the information on the household's ownership of consumer goods household characteristics, source of drinking water, toilet facilities, and a few other factors related to the household's socioeconomic status. The asset index was then constructed using the principal component analysis (PCA) [21] and adjusted for the urban and rural populations [22]. The DHS, being a household survey, allowed limited scope of extracting variables from the supply end of the health service delivery system. Group iv) Some of the important health service variables from mother's recall included in this analysis are the number of antenatal care (ANC) visits, type of ANC provider and type and assistance at delivery. We categorized the number of ANC visits as recommended by the $\mathrm{WHO}$ to facilitate interpretation of these practices. We coded number of ANC visits as no ANC visits, $1-3$ visits, and $\geq 4$ visits [23]. Type of antenatal care provider coded as medically trained and medically not-trained. We combined training status of care provider present during childbirth and the type of delivery into a single variable to indicate the service received by the women during delivery. We coded the combined variable as 'normal delivery by trained attendant', 'normal delivery by untrained attendant', 'caesarean delivery (by a trained attendant)'.

\section{Statistical analysis}

We examined delayed initiation of breastfeeding against a set of independent variables to explore the factors associated with delaying initiation beyond the first hour of birth. We used STATA version 15.0 (StataCorp, College Station, TX, USA) for all analyses. The analysis settings of the dataset were assigned using the command' svyset' to designate the sampling unit, survey weights and the cluster design of the survey. We calculated weighted frequencies for all potential explanatory variables and used descriptive statistics to explore the distribution of these factors, and used the binary outcome variable 'delayed initiation' for all logistic regression analysis. We applied univariate logistic regression to estimate the unadjusted association between the time of initiation of breastfeeding and potential explanatory factors. Then selected factors showing an independent association with $p<0.25$ for the initial multivariable logistic regression model. We included several factors with $p>0.25$ in univariate association in the initial model regardless of their level of significance as they were known to be associated with breastfeeding initiation. These factors included sex of the child, size of the child at birth, exposure to mass media, the person responsible for mother's healthcare decision, assistance at birth, mother's involvement in income generation activities. We constructed survey-weighted multiple logistic regression models to specify the association of all potential determinant variables as a function of a set of explanatory variables. To avoid non-convergence, we used the variance inflation factor to check for collinearity among variables included in the initial baseline model and further investigated for any strong associations among the variables by finding the correlation between continuous variables and by cross-tabulating categoric variables. Because of the moderate correlation $(r=0.6)$ between the mother's and father's education, we excluded the latter variable from the baseline model. We checked the continuous variable for body mass index for linearity assumptions. We removed non-significant variables that were not confounders or were not needed in the model using a backward elimination process, starting with the variable with the least significant association. The final multivariable model included some non-significant variables which were identified a priori to be important determinants of delayed initiation of breastfeeding. We report the adjusted OR with 95\% CI for all variables and interpreted statistical significance as $p<0.05$.

\section{Ethical considerations}

Data used in this study is publicly available and is deidentified for anonymity. We accessed the data through the DHS website (https://www.dhsprogram.com/data) after completion of the user's agreement and approval for use. Procedures and questionnaires for standard DHS surveys are reviewed and approved by the Institutional Review Board (IRB) at ICF International. ICF IRB 
ensures that the survey complied with the U. S Department of Health and Human Services regulations for the protection of human subjects [14]. Informed consent was obtained from all participants before interviewing them for the survey.

\section{Results}

There were 3205 (weighted) last-born children (live births) born in the 2 years preceding the survey who had information on the time of initiation of breastfeeding, and 1277 were born in any health facility. For this analysis, we included all the 1277 children who were born to women aged 15-49 years at any health facility and had information on the time of breastfeeding initiation. Figure 2 presents the distribution of delayed initiation of breastfeeding among all births, births at a health facility or at home. A total of $492(38.5 \%)$ children born at a health facility had their breastfeeding initiation delayed until after the first hour of birth.

The male to female ratio of the children born at a health facility was 55 to 45 . The majority of the women were not employed (81\%), were not placed on skin-toskin contact with their newborn (71.4\%) and gave birth through caesarean section (61.7\%). The mean age of the mothers at the time of pregnancy was $24 \pm 5$ years, and $22 \%$ of the mothers were adolescents. As we analyzed women who delivered at a health facility, $94 \%$ of the mothers had been to at least one ANC visit, but only $48 \%$ of these women had been to all four recommended ANC visits. The mean body mass index of the women was $22.3 \pm 4.1$. Three in five women (64\%) reported being able to take maternal healthcare decision either herself or jointly with her husband, and $11 \%$ were from the poorest wealth quintile.

Only $2.2 \%$ of the mothers never breastfed their child, and $92 \%$ of them were still breastfeeding at the time of the interview. The average time to initiate breastfeeding among all breastfed infants was $9.57 \pm 2.7 \mathrm{~h}$. However, the mean time to initiate breastfeeding among all infants delivered by a caesarean section was $13.12 \pm 4.24 \mathrm{~h}$, which is higher compared to children delivered through normal vaginal delivery assisted by a medically trained $(3.99 \pm 1.65 \mathrm{~h})$ and medically untrained birth attendant $(2.27 \pm 3.58 \mathrm{~h})$. The proportion of newborns with delayed initiation of breastfeeding was also higher for normal vaginal delivery by trained (46\%) and untrained (33\%) attendants in the health facilities compared to caesarean delivery (Table 1).

Table 2 shows the unadjusted and adjusted odds ratios of factors associated with delayed initiation of breastfeeding. Mothers who delivered through caesarean section had significantly higher unadjusted odds $(\mathrm{OR}=2.87$; 95\% CI 2.10, 3.92) of delaying initiation compared to mothers who gave birth through normal vaginal delivery in the presence of a medically trained birth attendant. Once adjusted for the clustering effect of the survey design and the other potential confounders, the risk of delaying initiation remained significantly high and unchanged among the caesarean deliveries (aOR 2.93; 95\% CI 2.17, 3.98). The likelihood of delayed initiation following caesarean delivery is higher than for women who had a normal vaginal delivery assisted by an untrained

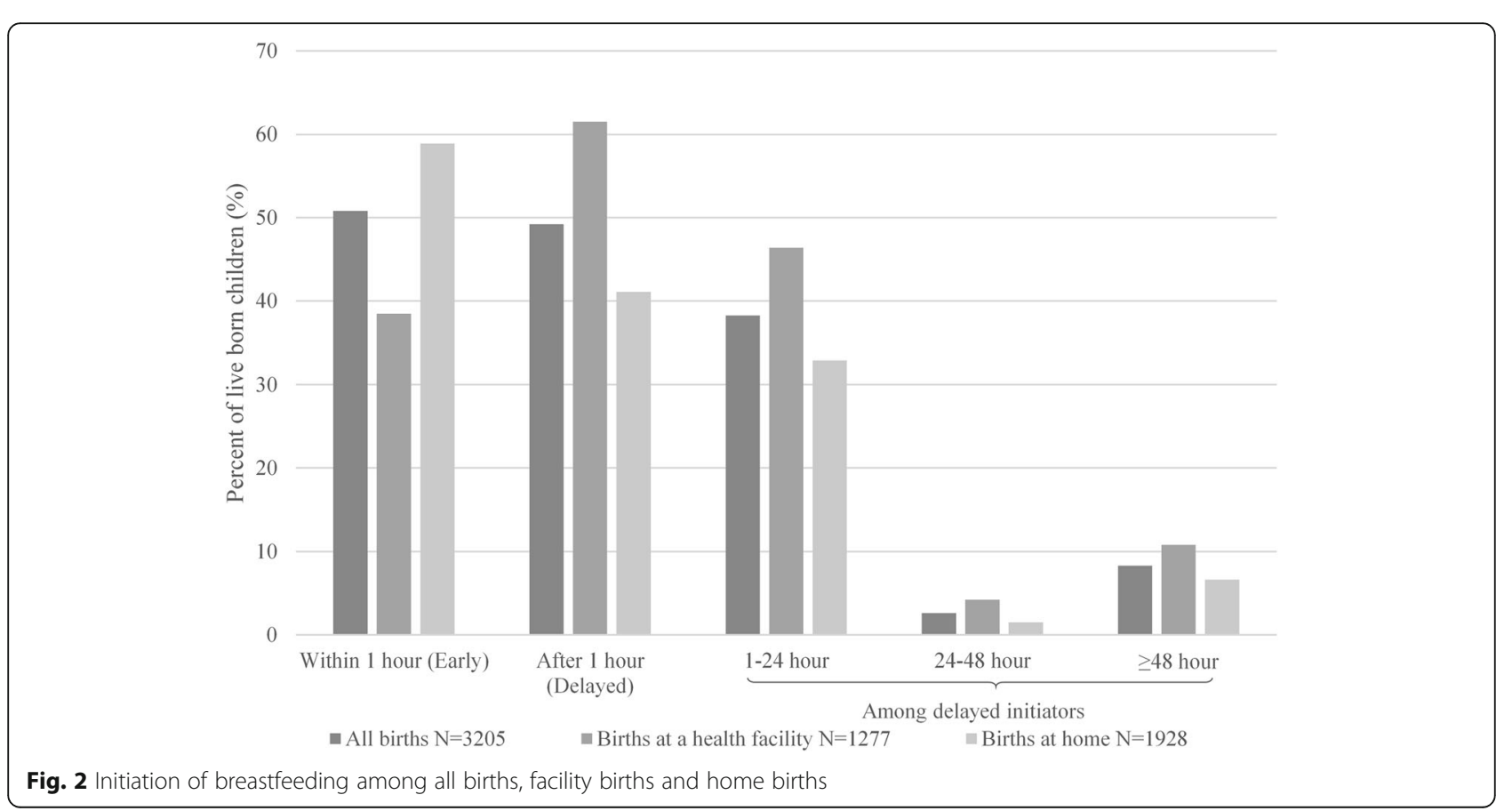


Table 1 Distribution of maternal, health service, infant and household characteristics among last-born children born the in the two years preceding the survey, 2014, $n=1277$ (weighted), and among children with breastfeeding initiation delayed after birth by more than one hour, $n=785$ (weighted)

\begin{tabular}{|c|c|c|}
\hline Characteristics & $\begin{array}{l}\text { Facility births } \\
n \text { (weighted) }=1277, n(\%)\end{array}$ & $\begin{array}{l}\text { Breastfeeding initiation delayed, } \geq 1 \mathrm{~h} \\
n \text { (weighted) }=785, n(\%)\end{array}$ \\
\hline \multicolumn{3}{|l|}{ Maternal characteristics } \\
\hline \multicolumn{3}{|l|}{ Mother's age } \\
\hline $15-19$ & $284(22.2)$ & $187(66.0)$ \\
\hline $20-29$ & $786(61.6)$ & $463(58.9)$ \\
\hline $30-39$ & $194(15.2)$ & $125(64.3)$ \\
\hline $40-49$ & $12.9(1.0)$ & $9(73.3)$ \\
\hline \multicolumn{3}{|l|}{ Religion } \\
\hline Islam & $1173(91.9)$ & $720(61.3)$ \\
\hline Other & $104(8.1)$ & $65(62.8)$ \\
\hline \multicolumn{3}{|l|}{ Mother's education } \\
\hline Higher & $249(19.5)$ & $160(63.9)$ \\
\hline Secondary & $699(54.8)$ & $439(62.8)$ \\
\hline Primary & $251(19.6)$ & $142(56.8)$ \\
\hline No Education & $78(6.1)$ & $44(56.5)$ \\
\hline \multicolumn{3}{|c|}{ Mother's involvement in income-generating activity } \\
\hline Employed & $246(19.3)$ & $147(59.7)$ \\
\hline Not employed & $1031(80.7)$ & $638(61.9)$ \\
\hline \multicolumn{3}{|l|}{ Parity } \\
\hline Primiparous & $636(49.8)$ & $408(64.2)$ \\
\hline Multiparous & $641(50.2)$ & $377(58.8)$ \\
\hline \multicolumn{3}{|c|}{ The person who takes the mother's healthcare-related decision } \\
\hline Woman alone & $128(10.1)$ & $71(55.9)$ \\
\hline Joint Decision & $678(53.6)$ & $428(63.2)$ \\
\hline Someone else (husband/partner/family) & $460(36.3)$ & $285(60.5)$ \\
\hline Body Mass Index & $22.3( \pm 4.1)$ & $22.6(4.0)$ \\
\hline \multicolumn{3}{|l|}{ Exposure to mass media } \\
\hline At least once a week & $872(68.3)$ & $531(60.8)$ \\
\hline Less than once a week or not at all & $405(31.7)$ & $254(62.8)$ \\
\hline \multicolumn{3}{|c|}{ Use of mobile phone to get health service or advice } \\
\hline Yes & $553(43.3)$ & $375(67.8)$ \\
\hline No & $724(56.7)$ & $409(56.6)$ \\
\hline \multicolumn{3}{|l|}{ Health service characteristics } \\
\hline \multicolumn{3}{|l|}{ Number of ANC visits } \\
\hline $4+\mathrm{ANC}$ & $611(47.8)$ & $396(64.8)$ \\
\hline 1-3 ANC & $593(46.4)$ & $345(58.1$ \\
\hline No ANC & $73(5.7)$ & $44(60.1)$ \\
\hline \multicolumn{3}{|l|}{ ANC Provider } \\
\hline Medically Trained & $1075(84.2)$ & $657(61.1)$ \\
\hline Medically not-trained & $202(15.8)$ & $128(63.3)$ \\
\hline \multicolumn{3}{|l|}{ Mode of delivery } \\
\hline Normal & 489 (38.3) & $224(45.9)$ \\
\hline C-section & $788(61.7)$ & $561(71.2)$ \\
\hline
\end{tabular}


Table 1 Distribution of maternal, health service, infant and household characteristics among last-born children born the in the two years preceding the survey, 2014, $n=1277$ (weighted), and among children with breastfeeding initiation delayed after birth by more than one hour, $n=785$ (weighted) (Continued)

\begin{tabular}{|c|c|c|}
\hline Characteristics & $\begin{array}{l}\text { Facility births } \\
n \text { (weighted) }=1277, n(\%)\end{array}$ & $\begin{array}{l}\text { Breastfeeding initiation delayed, } \geq 1 \mathrm{~h} \\
n \text { (weighted) }=785, n(\%)\end{array}$ \\
\hline \multicolumn{3}{|l|}{ Assistance at birth } \\
\hline Medically Trained & $1254(98.2)$ & $777(61.9)$ \\
\hline Medically not-trained & $23(1.8)$ & $8(35.3)$ \\
\hline \multicolumn{3}{|l|}{ Type and attendance at delivery } \\
\hline NVD by a trained attendant & $466(36.5)$ & $216(46.4)$ \\
\hline NVD by an untrained attendant & $23(1.8)$ & $8(33.3)$ \\
\hline C-section & $788(61.7)$ & $561(71.2)$ \\
\hline \multicolumn{3}{|l|}{ Infant characteristics } \\
\hline \multicolumn{3}{|l|}{ Sex of child } \\
\hline Male & $696(54.5)$ & $422(60.7)$ \\
\hline Female & $581(45.5)$ & $363(62.4)$ \\
\hline \multicolumn{3}{|l|}{ Size of the child at birth } \\
\hline Average or Larger & $1045(81.8)$ & $636(60.8)$ \\
\hline Smaller than average & $145(11.3)$ & $97(67.3)$ \\
\hline Very small & $87(6.8)$ & $52(59.3)$ \\
\hline \multicolumn{3}{|c|}{ The child put on skin-to-skin contact after delivery } \\
\hline Yes & $365(28.6)$ & $199(54.4)$ \\
\hline No & $912(71.4)$ & $586(64.3)$ \\
\hline \multicolumn{3}{|l|}{ Household characteristics } \\
\hline \multicolumn{3}{|l|}{ Paternal education } \\
\hline Higher & $323(25.3)$ & $200(61.8)$ \\
\hline Secondary & $488(38.2)$ & $294(60.2)$ \\
\hline Primary & $316(24.7)$ & $206(65.4)$ \\
\hline No Education & $150(11.8)$ & $85(56.8)$ \\
\hline \multicolumn{3}{|l|}{ Place of residence } \\
\hline Urban & $502(39.3)$ & $316(62.9)$ \\
\hline Rural & $775(60.7)$ & $469(60.5)$ \\
\hline \multicolumn{3}{|l|}{ Wealth quintile } \\
\hline Lowest & $139(10.9)$ & $86(62.2)$ \\
\hline Second & $152(11.9)$ & $97(63.9)$ \\
\hline Third & $216(16.9)$ & $123(56.8)$ \\
\hline Fourth & $334(26.1)$ & $205(61.4)$ \\
\hline Highest & $436(34.2)$ & $274(62.7)$ \\
\hline
\end{tabular}

Abbreviations: ANC antenatal care, NVD normal vaginal delivery, C-section caesarean section

birth attendant. The results also suggest that women who were pregnant for the first time were more likely to delay initiation compared to those who had previously given birth (aOR 0.71; 95\% CI 0.53, 0.96). Limiting exposure to any form of mass media to less than once a week or not at all is another likely risk factor (aOR 1.53; $95 \%$ CI 1.07, 2.19) of delaying initiation. Women with a higher body mass index also have higher odds of delaying breastfeeding initiation (aOR 1.05; 95\% CI 1.01,
1.11). None of the infant and household characteristics was significantly associated with the time of breastfeeding initiation.

\section{Discussion}

The prevalence of delayed initiation of breastfeeding beyond the first hour of birth was $61.5 \%$ among the newborns of the mothers who delivered at health facilities, which is high given that trained healthcare providers 
Table 2 Unadjusted and adjusted odds ratio of factors associated with breastfeeding initiation beyond the first hour of birth

\begin{tabular}{|c|c|c|c|c|}
\hline Characteristics & Unadjusted OR & $P$ - value & aOR $(95 \% \mathrm{Cl})^{\mathrm{a}}$ & $P$ - value \\
\hline \multicolumn{5}{|l|}{ Maternal characteristics } \\
\hline \multicolumn{5}{|l|}{ Mother's age } \\
\hline $15-19$ & 1.00 & 0.34 & - & \\
\hline $20-29$ & $0.74(0.53,1.05)$ & & & \\
\hline $30-39$ & $0.90(0.55,1.46)$ & & & \\
\hline $40-49$ & $1.42(0.30,6.63)$ & & & \\
\hline Religion & & & - & \\
\hline Islam & 1.00 & 0.88 & & \\
\hline Other & $1.03(0.66,1.62)$ & & & \\
\hline Mother's education & & & - & \\
\hline Higher & 1.00 & 0.60 & & \\
\hline Secondary & $0.98(0.70,1.36)$ & & & \\
\hline Primary & $0.75(0.47,1.22)$ & & & \\
\hline No Education & $0.76(0.40,1.42)$ & & & \\
\hline Mother's involvement in income-generating activity & & & - & \\
\hline Employed & 1.00 & 0.67 & & \\
\hline Not employed & $1.10(0.70,1.74)$ & & & \\
\hline \multicolumn{5}{|l|}{ Parity } \\
\hline Primiparous & 1.00 & 0.06 & & \\
\hline Multiparous & $0.78(0.61,1.01)$ & & $0.71(0.53,0.96)$ & 0.02 \\
\hline The person who takes the mother's healthcare-related decisions & & & - & \\
\hline Woman alone & 1.00 & 0.40 & & \\
\hline Joint Decision & $1.33(0.87,2.03)$ & & & \\
\hline Someone else (husband/partner/family) & $1.21(0.77,1.91)$ & & & \\
\hline Body Mass Index & $1.05(1.01,1.08)$ & 0.02 & $1.05(1.01,1.11)$ & 0.02 \\
\hline \multicolumn{5}{|l|}{ Exposure to mass media } \\
\hline At least once a week & 1.00 & 0.50 & & \\
\hline Less than once a week or not at all & $1.11(0.83,1.48)$ & & $1.53(1.07,2.19)$ & 0.02 \\
\hline Use of mobile phone to get health service or advice & & & - & \\
\hline Yes & 1.00 & 0.01 & & \\
\hline No & $0.62(0.45,0.86)$ & & & \\
\hline \multicolumn{5}{|l|}{ Health service characteristics } \\
\hline Number of ANC visits & & & - & \\
\hline $4+$ ANC & 1.00 & 0.26 & & \\
\hline $1-3$ ANC & $0.77(0.55,1.06)$ & & & \\
\hline No ANC & $0.82(0.45,1.51)$ & & & \\
\hline ANC Provider & & & - & \\
\hline Medically Trained & 1.00 & 0.65 & & \\
\hline Medically not-trained & $1.11(0.70,1.77)$ & & & \\
\hline Mode of delivery & & & - & \\
\hline Normal & 1.00 & 0.00 & & \\
\hline C-section & $2.94(2.16,3.99)$ & & & \\
\hline Assistance at birth & & & - & \\
\hline Medically Trained & 1.00 & 0.01 & & \\
\hline
\end{tabular}


Table 2 Unadjusted and adjusted odds ratio of factors associated with breastfeeding initiation beyond the first hour of birth (Continued)

\begin{tabular}{|c|c|c|c|c|}
\hline Characteristics & Unadjusted OR & $P$ - value & aOR $(95 \% \mathrm{Cl})^{\mathrm{a}}$ & $P$ - value \\
\hline Medically not-trained & $0.34(0.15,0.77)$ & & & \\
\hline \multicolumn{5}{|l|}{ Type and attendance at delivery } \\
\hline NVD by a trained attendant & 1.00 & 0.00 & & \\
\hline NVD by an untrained attendant & $0.59(0.25,1.42)$ & & $0.50(0.20,1.28)$ & 0.00 \\
\hline C-section & $2.87(2.10,3.92)$ & & $2.93(2.17,3.98)$ & \\
\hline \multicolumn{5}{|l|}{ Infant characteristics } \\
\hline Sex of child & & & - & \\
\hline Male & 1.00 & 0.62 & & \\
\hline Female & $1.07(0.82,1.39)$ & & & \\
\hline Size of the child at birth & & & - & \\
\hline Average or Larger & 1.00 & 0.35 & & \\
\hline Smaller than average & $1.38(0.89,2.13)$ & & & \\
\hline Very small & $0.94(0.55,1.60)$ & & & \\
\hline The child put on skin-to-skin contact after delivery & & & - & \\
\hline Yes & 1.00 & 0.01 & & \\
\hline No & $1.52(1.11,2.12)$ & & & \\
\hline \multicolumn{5}{|l|}{ Household characteristics } \\
\hline Paternal education & & & - & \\
\hline Higher & 1.00 & 0.72 & & \\
\hline Secondary & $0.96(0.71,1.30)$ & & & \\
\hline Primary & $1.18(0.78,1.78)$ & & & \\
\hline No Education & $0.83(0.44,1.57)$ & & & \\
\hline Place of residence & & & - & \\
\hline Urban & 1.00 & 0.54 & & \\
\hline Rural & $0.92(0.69,1.22)$ & & & \\
\hline Wealth quintile & & & - & \\
\hline Lowest & 1.00 & 0.84 & & \\
\hline Second & $1.07(0.58,1.97)$ & & & \\
\hline Third & $0.79(0.37,1.67)$ & & & \\
\hline Fourth & $0.95(0.57,1.59)$ & & & \\
\hline Highest & $1.00(0.61,1.66)$ & & & \\
\hline
\end{tabular}

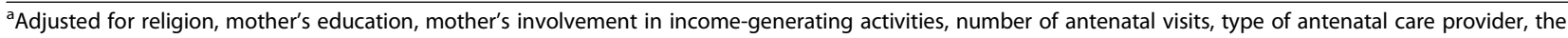
person who takes the mother's healthcare decision, sex of the child, size of child at birth, child put on skin-to-skin after delivery, place of residence, and wealth index

Abbreviations: $a O R$ adjusted odds ratio, OR odds ratio, ANC antenatal care, NVD normal vagina delivery, C-section caesarean section

attended these births. The odds of delaying initiation of breastfeeding were significantly higher for children born by caesarean section, first-time mothers, women not exposed to any form of media, and women who had a higher overall body mass index. Findings in this study highlight the need for program managers to design interventions facilitating improved breastfeeding initiation practices among women who deliver at a health facility. Such targeted interventions would be particularly important for Bangladesh and other developing countries where institutional deliveries have increased, and majority of the institutional deliveries are through caesarean section. The findings showed that delayed initiation of breastfeeding beyond the first hour of birth was more likely with caesarean delivery. The 2014 Bangladesh Demographic and Health Survey reported that $37 \%$ of all deliveries occurred at a health facility. Of these deliveries 6 out of every 10 were via caesarean section. In the same year, $23 \%$ of all newborns were delivered by caesarean section, which was an increase from only $4 \%$ in 2004 [14]. Even though a third of all deliveries occurred at a facility, the majority of them resulted in 
a caesarean section. Thus, it is important to address the breastfeeding initiation practices in a post caesarean section setting. Three out of five children in this study population were born through caesarean section, of whom 71\% delayed initiation beyond the first hour of birth. Delayed initiation was also higher for normal vaginal delivery assisted by trained and untrained providers at the health facilities. Although not a specific focus of this analysis, the proportion of delayed initiation among home deliveries $(n=1928)$, was similar when attended by either trained (44\%) or untrained (41\%) birth attendants.

A recent study [2] has established that caesarean delivery extends the time to initiation of breastfeeding because of several health facility-level factors. Women who deliver through caesarean section are also more likely to be unconscious after childbirth as a result of anaesthesia. Recommendations from World Health Organizations have suggested that in circumstances when the woman is unable to initiate breastfeeding as a result of medical procedures during childbirth, the newborn must be put to the breast as soon as the woman is conscious. If the woman received general anaesthesia during caesarean section, she could only initiate breastfeeding when she was awake and able to respond [24]. If the woman received regional anaesthesia during caesarean section, she could initiate breastfeeding even before the effects of the anaesthesia had worn off $[25,26]$. This approach would ensure that the first feeding occurred within the recommended time when she was alert and not in severe pain.

Our study uses data from a large nationally representative cluster survey that used a standardized methodology for collecting the data. We explored the factors associated with delayed initiation of breastfeeding among hospital deliveries using a sub-sample of the surveyed population. There are few studies from Bangladesh (and South Asia) that examine the factors associated with the time of breastfeeding initiation. A study by Islam et al. [27] found a higher likelihood of delaying initiation of breastfeeding in deliveries at health facilities. Our study has extended these findings by focusing just on the group of women who deliver at a health facility to identify the factors associated with delayed initiation of breastfeeding in that setting. The global recommendations for institutional deliveries if followed, should lead to lower rates of delayed initiation, but this does not appear to be the case in Bangladesh and other countries in South Asia [1]. Our study helps understand why these institutions are still failing to comply with the global recommendations for early initiation of breastfeeding.

An important limitation of using data from a DHS survey is its retrospective nature. The data is from a recall period of up to 5 years. Or it is collected after the occurrence of the event of interest. For the breastfeeding initiation variable, there was a recall period of 2 years. It is likely the mothers of severely ill newborns, and the mothers of newborns who died after being born alive would probably remember the time to initiation more accurately than mothers whose children were well. Secondly, breastfeeding initiation time was defined using the mother's report at the time of the survey. During a hospital delivery, especially in instances when the delivery is by caesarean section, the mother may not have been conscious immediately after childbirth to report the events around that time, including the time to initiation. Therefore, we have generated four broad breastfeeding initiation time categories: initiation within $1 \mathrm{~h}$ of birth, initiation from the first hour until the end of the first day after birth; initiation on the second day after birth; and initiation on or after the third day after birth. Thirdly, due to a lack of detailed health facility indicators, it was not possible to explore the effect of the knowledge and training status of the healthcare providers who assisted the women during childbirth. To account for this limitation, we have used some broad proxy indicators for whether or not the birth attendant was medically trained and linked this with the type of delivery. Additional modifiable factors like complications during pregnancy and delivery, duration of gestation, preterm delivery and newborn complications could not be included in this analysis as this information was not collected in the Bangladesh DHS. Fourthly, the body mass index used in this analysis was collected at the time of the survey and may not reflect the woman's BMI prepregnancy or during pregnancy.

The results of our study confirm prior findings that birth by caesarean section is a major barrier to timely initiation of breastfeeding among deliveries at a health facility. Several studies have explored the consequences and impact of caesarean deliveries on breastfeeding initiation. For most women, post-surgical pain and discomfort would have a negative influence on the timely initiation of breastfeeding [28, 29]. Women who have had medically induced labour and emergency caesarean section often experience prolonged labour. The stress associated with the difficult labour due to anaesthetics and labour inducing hormones [30-32], leads to a delay in mother-infant interactions and in the time to initiate breastfeeding [33]. Moreover, women who planned to give birth by elective caesarean delivery may not intend to breastfeed or are not comfortable with initiating the natural process of breastfeeding [29]. Often, delayed initiation following caesarean delivery is also associated with reduced suckling ability, insufficient milk supply $[31,33]$ and physiologic effects leading to delayed onset of lactogenesis [34].

One study [31] further suggested that the delayed initiation encountered by women who deliver by caesarean 
section at a health facility is preventable. One of the aims of the global approach of the Baby Friendly Hospital Initiative has been to raise the rates of early initiation. Within this initiative participating hospitals encouraged women to initiate breastfeeding immediately following birth, educated their medical staff on the importance of early initiation and consequences of delayed initiation, and enacted the policy of rooming-in of the mother and child [35]. Modification in some health facility practices has the potential to create an enabling environment to ensure the early initiation of breastfeeding. Strong leadership, staff training, all-staff participation, repeat education of medical staff and developing a strategic approach could be some of the strategies adopted in a health facility to promote timely initiation of breastfeeding. The revised BFHI [36] guidance recommends that even if mothers are not able to initiate breastfeeding within the first hour after birth, they should still receive support for skin-to-skin contact and to breastfeeding as soon as they are able.

We further found maternal body mass index (BMI) to be significantly associated with delayed initiation of breastfeeding. The mean BMI of all women in this analysis was 22.3 ( \pm 4.1$)$. The analysis indicates that for every unit increase in BMI, the likelihood of delaying initiation increases six times. Our findings confirm the results of earlier studies [37, 38] that reported a delayed 'onset of lactation' among women with high BMI. One study [37] found that mothers with BMI $>27 \mathrm{~kg} / \mathrm{m}^{2}$ were more than twice as likely to delay initiation than mothers with $\mathrm{BMI}<$ $27 \mathrm{~kg} / \mathrm{m}^{2}$. Another study [38] reported that for every oneunit increase in prepregnant BMI, there was a delay in the onset of lactation by $0.5 \mathrm{~h}$. A systematic review [39] looking at the relationship between maternal obesity and breastfeeding initiation presents the decrease in breastfeeding initiation rates among obese women, compared to women with normal weight and BMI. Most studies [4042] attributed the possible association between high BMI and delayed breastfeeding initiation to anatomical or physiological, psychological and cultural factors. Obese and overweight women tend to have mechanical difficulties of attaching the newborn to their breasts [41] and are likely to have obstetric complications often leading to caesarean deliveries [42].

Exposure to mass media in the form of listening to the radio, watching television and reading newspaper is linked to early initiation of breastfeeding [43]. Findings in this study suggest that exposure to any form of mass media once a week or more would to reduce the odds delaying breastfeeding initiation. A report by the BBC Media Action [44] reports in 2015 that $85 \%$ of the adult population in Bangladesh had access to television, and $42 \%$ had access to a radio. Moreover, $97 \%$ of Bangladeshi adults had access to a mobile phone. Such high levels of media access indicate that transmission of probreastfeeding messages via radio, television or a mobile phone platform could impact on the breastfeeding initiation practice by women and healthcare providers at health facilities alike. Studies in Bangladesh [45] and Vietnam [46] have found that combining a mass media campaign using multiple media platforms and interpersonal counselling positively impacted optimal breastfeeding practices.

\section{Conclusions}

Over the last decade many programs in developing countries, including Bangladesh, have promoted birthing at health facilities. Further, caesarean delivery at a health facility is a valuable tool to save the lives of women and their newborns in emergency obstetric situations [29, 47]. However, as we see from this analysis, the overuse of caesarean delivery in Bangladesh is associated with a higher likelihood of delaying breastfeeding initiation. Research also suggests that delayed initiation is likely to increase the risk of mortality and morbidity, especially in the newborn [5] and early newborn period [6, 10, 19]. These findings suggest that it is important for health facilities to establish guidelines on immediate newborn care practices to ensure early initiation following caesarean delivery. There is a need for national-level policies to provide a supportive environment at health facilities. These policies should include clinical guidelines and protocols for the successful initiation of breastfeeding following caesarean delivery. Interventions like the BFHI [48] have already demonstrated how training and knowledge transfer interventions support appropriate breastfeeding practices in hospitals in low- and middle-income countries. There will be a need for a consultative process to develop relevant guidelines and to test their effectiveness before upscaling to hospitals across Bangladesh. Such interventions would further have the potential to successfully institutionalize improved breastfeeding initiation practices following hospital deliveries in other South Asian countries. Future research needs to help develop and test clinical guidelines for ensuring early initiation of breastfeeding in health facilities, especially following caesarean delivery.

\section{Abbreviations \\ ANC: Antenatal care; BFHI: Baby Friendly Hospital Initiative; BMI: Body Mass Index; Cl: Confidence Interval; DHS: Demographic and Health Survey; EA: Enumeration areas; IRB: Institutional Review Board; OR: Odds Ratio; PCA: Principal Component Analysis; UNICEF: United Nations Children's Fund; WHO: World Health Organization}

\section{Acknowledgements}

The authors would like to thank the measure DHS program for granting access to the Bangladesh 2014 dataset for this analysis. The primary author [SR] would also like to thank the Australian government and the Endeavour Postgraduate Scholarship Program for funding and supporting her PhD program at The University of Sydney School of Public Health. 


\section{Authors' contributions}

SR: designed and conducted the research, analyzed data, wrote the paper, and had primary responsibility for final content; MJD: provided critical guidance on statistical analysis; TMH, and AA: critically reviewed the manuscript; and all authors: read and approved the final manuscript.

\section{Funding}

The author SR received the Endeavour Postgraduate Scholarship from the Australian Government Department of Education for her PhD work.

\section{Availability of data and materials}

The datasets analysed during the current study are publicly available through the Demographic and Health Survey website [https://www. dhsprogram.com/data].

\section{Ethics approval and consent to participate}

This data collection was conducted according to the guidelines laid down in the Declaration of Helsinki, and all procedures involving research study participants were approved by the Institutional Review Board (IRB) at ICF International. Written informed consent was obtained from all study participants.

\section{Consent for publication}

Not applicable.

\section{Competing interests}

All authors declare that they have no competing interests.

\section{Received: 30 September 2020 Accepted: 12 January 2021}

Published online: 22 January 2021

\section{References}

1. UNICEF And World Health Organization. Capture the moment: Early initiation of breastfeeding: The best start for every newborn. New York: UNICEF; 2018.

2. Takahashi K, Ganchimeg T, Ota E, Vogel JP, Souza JP, Laopaiboon M, et al. Prevalence of early initiation of breastfeeding and determinants of delayed initiation of breastfeeding: secondary analysis of the WHO global survey. Sci Rep. 2017;7:44868.

3. Exavery A, Kante AM, Hingora A, Phillips JF. Determinants of early initiation of breastfeeding in rural Tanzania. Int Breastfeed J. 2015;10:27.

4. Edmond KM, Zandoh C, Quigley MA, Amenga-Etego S, Owusu-Agyei S, Kirkwood BR. Delayed breastfeeding initiation increases risk of neonatal mortality. Pediatrics. 2006;117(3):e380-6.

5. Khan J, Vesel L, Bahl R, Martines JC. Timing of breastfeeding initiation and exclusivity of breastfeeding during the first month of life: effects on neonatal mortality and morbidity--a systematic review and meta-analysis. Matern Child Health J. 2015;19(3):468-79.

6. Smith ER, Hurt L, Chowdhury R, Sinha B, Fawzi W, Edmond KM, Neovita Study G. Delayed breastfeeding initiation and infant survival: a systematic review and meta-analysis. PLoS One. 2017;12(7):e0180722.

7. Friedrich MJ. Early initiation of breastfeeding. JAMA. 2018;320(11):1097.

8. Edmond KM, Kirkwood BR, Amenga-Etego S, Owusu-Agyei S, Hurt LS. Effect of early infant feeding practices on infection-specific neonatal mortality: an investigation of the causal links with observational data from rural Ghana. Am J Clin Nutr. 2007;86(4):1126-31.

9. Garcia C, Mullany LC, Rahmathullah L, Katz J, Thulasiraj R, Sheeladevi S, et al. Breast-feeding initiation time and neonatal mortality risk among newborns in South India. J Perinatol. 2011:31(6):397-403.

10. Raihana S, Dibley MJ, Rahman MM, Tahsina T, Siddique MAB, Rahman QS, et al. Early initiation of breastfeeding and severe illness in the early newborn period: an observational study in rural Bangladesh. PLoS Med. 2019;16(8):e1002904.

11. World Health Organization. Infant and young child feeding: a tool for assessing national practices, policies and programmes. Geneva: WHO; 2003.

12. World Health Organization. Guideline: protecting, promoting and supporting breastfeeding in facilities providing maternity and newborn services. Geneva: World Health Organization; 2017.

13. Mullany LC, Katz J, Li YM, Khatry SK, LeClerq SC, Darmstadt GL, et al. Breastfeeding patterns, time to initiation, and mortality risk among newborns in southern Nepal. J Nutr. 2008;138(3):599-603.
14. National Institute of Population Research and Training (NIPORT); Mitra and Associates; and ICF International. Bangladesh Demographic and Health Survey 2014. Dhaka, Bangladesh, and Rockville, Maryland, USA: NIPORT, Mitra and Associates, and ICF International.; 2016.

15. National Institute of Population Research and Training (NIPORT); Mitra and Associates; and ICF International. Bangladesh Demographic and Health Survey 2004. Dhaka, Bangladesh, and Rockville, Maryland, USA: NIPORT, Mitra and Associates, and ICF International.; 2005.

16. Croft TN, Marshall AM, Allen CK. Guide to DHS statistics. Rockville: ICF; 2018.

17. Esteves TM, Daumas RP, Oliveira MI, Andrade CA, Leite IC. Factors associated to breastfeeding in the first hour of life: systematic review. Rev Saude Publica. 2014;48(4):697-708.

18. Hector D, King L, Webb K, Heywood P. Factors affecting breastfeeding practices: applying a conceptual framework. N S W Public Health Bull. 2005; 16(3-4):52-5.

19. Sharma IK, Byrne A. Early initiation of breastfeeding: a systematic literature review of factors and barriers in South Asia. Int Breastfeed J. 2016:11:17.

20. Channon AA. Can mothers judge the size of their newborn? Assessing the determinants of a mother's perception of a baby's size at birth. J Biosoc Sci. 2011;43(5):555-73.

21. Zeng $L$, Yan $H$, Chen Z. Measurement of the living standards of family in rural area and relationship between wealth index and perinatal care status. Wei Sheng Yan Jiu. 2008;37(6):714-7.

22. Shea OR, Rutstein R. The DHS wealth index: approaches for rural and urban areas. Calverton: Demographic and Health Research Division, Macro International Inc; 2008. p. 60.

23. World Health Organization. WHO Recommendations on Antenatal Care for a Positive Pregnancy Experience. Geneva: World Health Organization; 2016.

24. Lauwers J, Swisher A. Counseling the Nursing Mother: Jones \& Bartlett Publishers; 2015.

25. Parthasarathy S, Rajah C. Feasibility of early breast feeding after caesarean section. Sri Lanka J Child Health. 2011:40:11-2.

26. Stevens J, Schmied V, Burns E, Dahlen H. Immediate or early skin-to-skin contact after a caesarean section: a review of the literature. Matern Child Nutr. 2014;10(4):456-73.

27. Islam MA, Mamun A, Hossain MM, Bharati P, Saw A, Lestrel PE, et al. Prevalence and factors associated with early initiation of breastfeeding among Bangladeshi mothers: a nationwide cross-sectional study. PLoS One. 2019;14(4):e0215733.

28. Albokhary AA, James JP. Does cesarean section have an impact on the successful initiation of breastfeeding in Saudi Arabia? Saudi Med J. 2014 35(11):1400-3.

29. Kuyper E, Vitta B, Dewey K. Implications of cesarean delivery for breastfeeding outcomes and strategies to support breastfeeding. Alive Thrive Tech Brief. 2014:8:1-9.

30. Ahluwalia IB, Li R, Morrow B. Breastfeeding practices: does method of delivery matter? Matern Child Health J. 2012:16(Suppl 2):231-7.

31. Rowe-Murray HJ, Fisher JR. Baby friendly hospital practices: cesarean section is a persistent barrier to early initiation of breastfeeding. Birth. 2002;29(2):124-31.

32. Zanardo V, Svegliado G, Cavallin F, Giustardi A, Cosmi E, Litta P, et al. Elective cesarean delivery: does it have a negative effect on breastfeeding? Birth. 2010;37(4):275-9

33. Hobbs AJ, Mannion CA, McDonald SW, Brockway M, Tough SC. The impact of caesarean section on breastfeeding initiation, duration and difficulties in the first four months postpartum. BMC Pregnancy Childbirth. 2016:16:90.

34. Scott JA, Binns CW, Oddy WH. Predictors of delayed onset of lactation. Matern Child Nutr. 2007;3(3):186-93.

35. Hannon PR, Ehlert-Abler P, Aberman S, Williams R, Carlos M. A multidisciplinary approach to promoting a baby friendly environment at an urban university medical center. J Hum Lact. 1999;15(4):289-96.

36. World Health Organization. Implementation guidance: protecting promoting and supporting breastfeeding in facilities providing maternity and newborn services: the revised baby-friendly hospital initiative. Geneva: WHO; 2018

37. Dewey KG, Nommsen-Rivers LA, Heinig MJ, Cohen RJ. Risk factors for suboptimal infant breastfeeding behavior, delayed onset of lactation, and excess neonatal weight loss. Pediatrics. 2003;112(3 Pt 1):607-19.

38. Hilson JA, Rasmussen KM, Kjolhede CL. High prepregnant body mass index is associated with poor lactation outcomes among white, rural women independent of psychosocial and demographic correlates. J Hum Lact. 2004;20(1):18-29. 
39. Turcksin R, Bel S, Galjaard S, Devlieger R. Maternal obesity and breastfeeding intention, initiation, intensity and duration: a systematic review. Matern Child Nutr. 2014;10(2):166-83.

40. Kitsantas P, Pawloski LR. Maternal obesity, health status during pregnancy, and breastfeeding initiation and duration. J Matern Fetal Neonatal Med. 2010;23(2):135-41.

41. Donath SM, Amir LH. Does maternal obesity adversely affect breastfeeding initiation and duration? J Paediatr Child Health. 2000;36(5):482-6.

42. Amir LH, Donath S. A systematic review of maternal obesity and breastfeeding intention, initiation and duration. BMC Pregnancy Childbirth. 2007;7:9.

43. Seidu AA, Ameyaw EK, Ahinkorah BO, Bonsu F. Determinants of early initiation of breastfeeding in Ghana: a population-based cross-sectional study using the 2014 demographic and health survey data. BMC Pregnancy Childbirth. 2020:20:632.

44. BBC Media Action. Strengthening accountability through media in Bangladesh. 2017 [https://dataportal.bbcmediaaction.org/site/assets/ uploads/2016/09/Bangladesh-Country-Report-2017.pdf].

45. Menon P, Nguyen PH, Saha KK, Khaled A, Sanghvi T, Baker J, et al. Combining intensive counseling by frontline workers with a nationwide mass media campaign has large differential impacts on complementary feeding practices but not on child growth: results of a cluster-randomized program evaluation in Bangladesh. J Nutr. 2016;146(10):2075-84.

46. Menon P, Nguyen PH, Saha KK, Khaled A, Kennedy A, Tran LM, et al. Impacts on breastfeeding practices of at-scale strategies that combine intensive interpersonal counseling, mass media, and community mobilization: results of cluster-randomized program evaluations in Bangladesh and Viet Nam. PLoS Med. 2016;13(10):e1002159.

47. Bailey P, Lobis S, Maine D, Fortney JA. Monitoring Emergency Obstetric Care: a handbook: World Health Organization; 2009.

48. World Health Organization and UNICEF. Baby-Friendly Hospital Initiative: revised, updated and expanded for integrated care. Geneva: WHO; 2009

\section{Publisher's Note}

Springer Nature remains neutral with regard to jurisdictional claims in published maps and institutional affiliations.

Ready to submit your research? Choose BMC and benefit from:

- fast, convenient online submission

- thorough peer review by experienced researchers in your field

- rapid publication on acceptance

- support for research data, including large and complex data types

- gold Open Access which fosters wider collaboration and increased citations

- maximum visibility for your research: over $100 \mathrm{M}$ website views per year

At $\mathrm{BMC}$, research is always in progress.

Learn more biomedcentral.com/submissions 